\title{
On the Factors that Affect Airline Flight Frequency and Aircraft Size*
}

\author{
Vivek Pai \\ University of California, Irvine \\ Department of Economics \\ e-mail: vpai@uci.edu
}

November 5, 2007

\begin{abstract}
This paper assesses the determinants of aircraft size and frequency of flights on airline routes by considering market demographics, airport characteristics, airline characteristics and route characteristics. The paper shows that frequency and aircraft size increase with population, income, and runway length. An increase in the proportion of managerial workers in the labor force or the proportion of population below the age of 25 results in greater frequency with the use of small planes. Slot constrained airports and an increase in the number of nearby airports lead to lower flight frequency with the use of smaller planes. Hubs and low cost carriers are associated with larger plane sizes and higher frequency, while regional airline ownership leads to higher frequency and the use of smaller planes. An increase in distance between the endpoints leads to lower frequency with the use of larger planes. As airport delay rises, airlines reduce frequency and use smaller planes, though when airport cancellations rise, flight frequency increases with the use of larger planes. This finding suggests airlines utilize frequency and aircraft size to hedge against flight cancellations.
\end{abstract}

\footnotetext{
*I thank Jan Brueckner, Volodymyr Bilotkach, Linda Cohen, Iris Franz, Nick Rupp, Ken Small, Kurt Van Dender, and Kat Wong for their feedback. I'm grateful to the University of California Transportation Center for generous financial support. Credit for any errors remains with the author.
} 


\section{Introduction}

Flight delays have become rampant in the airline industry. US on-time performance for the summer of 2007 has been the worst on record, with over 30 percent of all commercial flights delayed. Airlines blame bad weather and an outdated air traffic control system. Government officials blame airlines for scheduling more flights than the system is designed to handle. At the same time, airlines are utilizing small regional aircraft, which are capable of carrying between 30 and 100 passengers, in greater numbers than ever before. These smaller planes utilize the same resources as larger planes in terms of landing slots and air traffic control, while carrying fewer passengers than mainline aircraft. What factors lead airlines to exacerbate the problems of over-utilized infrastructure by using smaller aircraft with greater frequency over larger aircraft? This paper attempts to answer this question by examining the determinants of aircraft sizes and the frequency of flights between airports.

Airlines may choose to serve a market ${ }^{1}$ with a particular aircraft size and frequency due to various population, market, and airport characteristics. A market that has a high concentration of passengers with high time costs (business travelers) might be served by smaller aircraft with greater frequency, while a market with a high concentration of low time cost passengers (leisure travelers) might be serviced by larger aircraft with lower frequency. Conversely, markets with a high concentration of business or affluent passengers could benefit from the use of larger jets, as they have more first class seats, than markets with fewer business or affluent passengers. Distance is also a significant factor in the use of a particular aircraft type on a route. As the distance between the two endpoints increases, longer-range (and thus larger) aircraft are needed.

\footnotetext{
${ }^{1}$ In this paper, the term market is used to describe a direct route between two cities. In actuality a city-pair market is the market for travel between two cities without regard to the route taken. For example, the routing may involve a connection at a hub airport rather than a non-stop flight. The paper's convenient, but inexact, use of the term market should be borne in mind.
} 
The determinants of aircraft size and frequency have major policy implications, especially with respect to congestion and landing fees. Federal Aviation Administration officials have proposed aircraft size targets at New York's LaGuardia airport, as airlines' use of regional jets over mainline jets in the airport's limited number of landing slots has led to high congestion and under-utilization of passenger terminals. A minimum size requirement, however, may lead to under-provision of desired flight frequencies or over-provision of seat capacity. Thus, while a seat requirement may lead to more efficient use of terminal infrastructure, such a policy may ultimately reduce total welfare. A thorough understanding of the determinants of aircraft size and flight frequency will allow policy makers to better judge the outcomes of proposed policies.

Researchers have paid some attention to the determinants of aircraft size and frequency in city-pair markets. Bhadra (2005) constructs a multinomial logit regression using the number of passengers, distance, and the type of airport hub at the route endpoints to explain aircraft choice in the US. A self-noted shortcoming of the model is that neither airline behavior, nor economic factors affecting passenger demand, are considered in explaining aircraft choice. Givoni and Rietveld (2006) take a different approach by considering the implications of route factors and airport characteristics on the aircraft size decision. Using OLS, the authors investigate the impact of distance, market size, market concentration, slot constraints, hub status, and the number of runways on aircraft choice on over 500 routes in the US, Europe and Asia. Givoni and Rietveld find that the choice of aircraft size is mainly influenced by route characteristics, including distance, level of demand, and competition. The authors further find that airport characteristics, such as the number of runways and whether the airport is a hub or slot constrained, do not influence aircraft choice.

Other factors may also influence aircraft sizes. An airline may opt to use larger aircraft on a route due to economies of scale in aircraft operation. ${ }^{2}$ This effect, however, may be offset

\footnotetext{
${ }^{2}$ As noted by Babikian, et al (2002), smaller regional jets have lower fixed costs, though their operating costs are
} 
by higher labor costs. Pilots receive higher salaries for flying larger aircraft, leading airlines to prefer in some cases the use of smaller aircraft in short-haul, high density markets (Wei and Hansen, 2003). Forbes and Lederman (2005) consider the relationship between service quality and the integration of regional carriers with major airlines. On routes where schedule disruptions are costly to the major carrier and likely to occur (i.e., on hub routes and routesprone to bad weather), the authors show that major airlines are likely to rely on their regional carrier subsidiaries, rather than on independent regional carriers. Thus, factors such as unit costs and relationship to regional carriers may play a factor in an airline's aircraft size and frequency decisions.

This study focuses on the US market and uses 4 groups of explanatory variables to investigate the determinants of aircraft size and flight frequency: market demographics, airport characteristics, airline characteristics and route characteristics. These explanatory variables provide insight into the demand characteristics and operational constraints that airlines face in making aircraft size and frequency decisions. This approach differs from past studies that consider operational constraints without any attention to demand factors. In a departure from the current literature, the study uses several continuous variables as hub controls instead of a dummy variable. Such an approach allows for deeper analysis of "focus cities," cities that have service to many destinations, but are not considered a hub by the carrier. In addition, the impact of delays and cancellations on frequency and aircraft size are considered.

This study finds that frequency and aircraft size increase with population and income at the route endpoints. An increase in the proportion of managers in the workforce or the percentage of the population below 25 years of age results in greater frequency and the use of smaller planes. With respect to airport characteristics, as consistent with previous literature, an increase in runway length results in higher frequency and larger plane sizes. Airport slot higher. Conversely, large jets have low operating and high fixed costs. 
constraints and the existence of more airports in the vicinity lead to lower flight frequency and smaller planes. Hub airports and low cost carriers are associated with larger plane sizes and higher frequency, though regional airline ownership by the major carrier leads to higher frequency and the use of smaller planes. An increase in distance between the endpoints leads to lower frequency and the use of larger planes. An increase in average delay at an endpoint leads airlines to provide lower frequency and to use smaller planes, though an increase in cancellations leads to higher flight frequency and use of larger planes. This finding suggests that airlines utilize aircraft size and frequency to hedge against flight cancellations.

The paper has 5 sections. The following section introduces a theoretical framework to motivate the empirical work. Section 3 provides a description of the data, while Section 4 discusses empirical results. The last section offers some concluding remarks.

\section{Theoretical Framework and Implications}

To understand the implications of demographics on aircraft size and frequency, a review of the monopoly scheduling model of Brueckner (2004) is useful. For simplicity, the airline serves three equidistant cities, A, B, and H, as shown in Figure 1. Demand for travel exists between each pair of cities, yielding three city-pair markets: $\mathrm{AH}, \mathrm{BH}$, and $\mathrm{AB}$. In a point-to-point network, the airline operates flights between each pair of cities, so that nonstop travel occurs in each city-pair market. In a hub-spoke network, the airline only operates flights to the hub H. Therefore, flights in the hub-spoke network carry both local (passengers in markets AH or $\mathrm{BH})$ as well as connecting passengers (passengers in market $\mathrm{AB}$ ).

Travel demand is identical in the three city-pair markets, and thus the airline faces the same inverse demand function in each market, derived as follows. Passengers must commit to travel before knowing their preferred departure time. Letting $T$ denote the time circumference of the 
circle (representing a day), the passenger's utility is dependent on expected schedule delay, ${ }^{3}$ which equals $T / 4 f$, where $f$ is the number of (evenly spaced) flights operated by the airline. Letting $\nu$ denote a disutility parameter, the cost of schedule delay is $\nu T / 4 f$. Setting $\gamma$ equal to $\nu T / 4$, this cost becomes $\gamma / f$. In addition, connecting passengers have to incur additional travel costs (including extra travel time as well as the inconvenience of changing planes) that local passengers avoid. The extra cost of traveling indirectly is denoted $\mu$. Following Brueckner (2004), the airline's inverse market demand function is then

$$
p=\alpha-\beta q-\gamma / f-\mu,
$$

where $p$ is the price and $q$ is the number of passengers.

Letting $s$ denote the number of seats per flight, the cost function of the airline involves two parameters, a fixed cost, $\theta$, and a marginal cost per seat, $\tau$ :

$$
c(s)=\theta+\tau s .
$$

For simplicity, all seats on an aircraft are assumed to be filled, which implies that the number of seats per flight must equal total passengers divided by the frequency of flights:

$$
s=q / f .
$$

With the above demand and cost functions, profit functions for both the point-to-point and hub-spoke networks can be derived. In a point-to-point network, the total cost for each route is equal to $f c(s)$. After substituting (3) into (2) and rearranging, total costs per route can be

\footnotetext{
${ }^{3}$ To derive expected schedule delay, suppose that the airline's flights are evenly spaced around the clock, with $T$ denoting the number of available hours. Then, letting $f$ denote the number of flights, the time interval between flights is $T / f$. The average time between flights is $T / 2 f$, and expected schedule delay is $T / 4 f$, assuming a uniform distribution of desired departure times.
} 
written as $f \theta+\tau q$. Subtracting the total cost per route from revenue per route, as obtained by multiplying (1) by the number of passengers on the route, profit for a point-to-point network equals

$$
\pi^{p p}=3[(\alpha-\beta q-\gamma / f) q-f \theta-\tau q]
$$

where the factor of 3 reflects the 3 routes in the network, as presented in Figure 1. Note that in the point-to-point network, $\mu$ is 0 , as all passengers travel direct to their destination and therefore do not incur any additional travel time costs.

The profit function for a hub-spoke network differs from that in a point-to-point network. In the hub-spoke case, flight frequency on each of the two routes is denoted $f_{h}$. Local passengers are denoted $q_{h}$, while connecting traffic is denoted $Q$. Since a hub-spoke network creates an asymmetry between the AB market and the other two direct markets, $q_{h}$ and $Q$ will not be equal. Likewise, the fare for connecting passengers in the $\mathrm{AB}$ market is set independently of the fares for local passengers, not being simply the sum of the fares from $\mathrm{A}$ to $\mathrm{H}$ and from $\mathrm{H}$ to B. From (1), local fares are given by $p_{h}=\alpha-\beta q_{h}-\gamma / f_{h}$. Like in the point-to-point network, local passengers travel direct and therefore do not incur any additional travel time costs, so that $\mu=0$. However, since $\mathrm{AB}$ passengers incur a connection cost, the fare in the $\mathrm{AB}$ market is equal to $P=\alpha-\beta Q-\gamma / f_{h}-\mu$.

Since connecting passengers must travel on both hub-spoke routes, passenger volume on each route is equal to is equal to $q_{h}+Q$, resulting in an aircraft size of $s_{h}=\left(q_{h}+Q\right) / f_{h}$. After substituting the aircraft size on hub-spoke routes into (3) and multiplying by the number of routes flown, total hub-spoke network costs are $2\left[f_{h} \theta+\tau\left(q_{h}+Q\right)\right]$. With the airline earning revenue from two local markets as well as the connecting market, hub-spoke network profit is

$$
\pi^{h s}=2 q_{h}\left(\alpha-\beta q_{h}-\gamma / f_{h}\right)+Q\left(\alpha-\mu-\beta q_{h}-\gamma / f_{h}\right)-2 \theta f_{h}-2 \tau\left(q_{h}+Q\right) .
$$


After analysis of the first order conditions for profit maximization, Brueckner (2004) finds the following results:

1. Flight frequency increases, irrespective of network type, when:

(a) the demand intercept $\alpha$ rises or the demand curve slope $\beta$ falls (shifting the demand curve outward).

(b) fixed $\operatorname{cost} \theta$ or marginal seat $\operatorname{cost} \tau$ falls.

(c) schedule delay cost $\gamma$ rises.

2. As the cost of layover time for connecting passengers, $\mu$, increases, hub-spoke frequency $f_{h}$, local hub-spoke passengers $q_{h}$ and connecting hub-spoke passengers $Q$ all decline.

3. Irrespective of network type, aircraft size $s$ increases when:

(a) the demand intercept $\alpha$ rises or the demand curve slope $\beta$ falls.

(b) marginal seat cost $\tau$ falls.

4. Flight frequency is higher in a hub-spoke network than in a point-to-point network

5. Aircraft sizes are larger in a hub-spoke network than in a point-to-point network

With the comparative-static results presented above, expected empirical outcomes can be predicted. Since demand for travel is cyclical, with higher demand during the summer, quarterly dummy variables should indicate higher frequency and larger plane sizes during peak travel periods, which are the 2nd and 3rd quarters. Population would also shift the demand intercept $\alpha$ in the theoretical model. Thus, as population levels $(\alpha)$ increase, frequency and aircraft size should increase. Since households with high incomes also demand more air travel, an increase in income should also raise frequency and aircraft size.

Business travel is undertaken by managers who have high values of time. Therefore, managers would have a high $\gamma$, which results in high flight frequency in markets that serve managers. High income households also have a high opportunity cost of time and thus, like managers, have a high $\gamma$, leading to higher frequency in high-income markets. This effect reinforces the 
increase in flight frequency brought about through the higher demand associated with high incomes. But due to their high values of time, managers and high income households also have a high cost of layover time $\mu$. With a high $\gamma$ value raising frequency and a high $\mu$ lowering it, the ultimate effect on frequency of an increase in the number of managers and high income households is thus ambiguous. This ambiguity disappears, however, in a point-to-point network, where $\mu=0$. Also note that the effect of an increase $\gamma$ on aircraft size is ambiguous. Though these results are derived for a monopoly model, similar results hold in a competitive model (Brueckner and Flores-Fillol, 2007).

Low cost carriers (LCCs), like Southwest, operate point-to-point networks. Therefore, a LCC control variable might be expected to have a negative effect on aircraft size and frequency, given predictions (4) and (5) above. These predictions, however, may not hold given the contrasting markets served by LCCs and traditional, hub-spoke carriers. Hub-spoke carriers often serve small towns through the use of turboprop and regional jets, while low-cost carriers usually serve larger cities with larger aircraft. This disparity can be seen in Table 1, where cities that have service by a LCC are much larger than cities that do not have such service. Since this service pattern means that LCCs do not own turboprops and regional jets, LCC service might then be associated with larger than average aircraft. In addition, while the model implies higher frequency in hub-spoke networks, suggesting that the LCC effect on frequency should be negative, this effect may not be present given the different nature of LCCs.

Past empirical studies have shown the effect of hub endpoints to be positive for both frequency and aircraft size (Givoni and Rietveld, 2006), as theoretically stated above. This paper, unlike related studies, uses the share of passengers connecting at the airport and number of destinations served as hub controls instead of a dummy variable. Hub cities have high 
connecting shares along with service to a large number of endpoints. Some non-hub cities, however, have appreciable values of these variables, as seen in Table 8 in the appendix. In line with past literature, it is expected that aircraft size and frequency rise as the share of passengers that connect and the number of destinations increase. In addition, as suggested by Forbes and Lederman (2005), major airlines that own regional carriers may have a greater ability to dictate flight schedules and aircraft usage than carriers that rely on contract partners. This effect would suggest that major ownership of a regional carrier would allow greater flight frequency and the use of smaller planes.

Past literature has shown that, as distance between the two endpoints increases, aircraft size increases and frequency decreases (Givoni and Rietveld, 2006). In addition, for large aircraft to land and take off, an airport must have longer runways. Therefore aircraft size should have a positive relationship with runway length.

For a fixed population, the presence of nearby airports will split passengers among several airports and therefore result in lower frequency and the use of smaller aircraft at a given airport. Givoni and Rietveld (2006) also find that slot constraints lead to smaller aircraft, though the result is not statistically significant. While Givoni and Rietveld (2006) do not consider frequency, it would be expected that slot constraints would lower flight frequency. Finally, delays and cancellations cause uncertainty for passengers and airlines in terms of expected arrival times and operations, respectively. While Rupp and Homes (2005) suggest that airlines will not cancel flights if frequency is low, the effect of operational uncertainty, as measured by airport-level delays and cancellations, on aircraft size and frequency is hard to predict. 


\section{Empirical Model and Data}

To conduct this study, the following regression model is estimated:

$$
G_{i j k t}=\alpha_{i j k t}+\beta_{1} W_{i}+\beta_{2} W_{j}+\beta_{3} X_{i k t}+\beta_{4} X_{j k t}+\beta_{5} Y_{k}+\beta_{6} Z_{i j}+v_{i j k t}
$$

where $G_{i j k t}$ is the dependent variable (frequency or aircraft size) on the route from airport $i$ to airport $j$ on airline $k$ in month $t$, and $v_{i j k t}$ is the error term. Many studies that focus on the airline industry remove directionality in the data (i.e., treat flights from $j$ to $i$ the same as flights from $i$ to $j$ ). Due to the nature of the hub control variables used in this study, however, the directional nature of the data is retained. $W_{i}$ and $W_{j}$ are vectors of airport specific characteristics as well as population demographics for the cities where airport $i$ and $j$ are located, respectively. $X_{i k t}$ and $X_{j k t}$ are vectors of airline-specific hub and operational characteristics for each airport in a given month. $Y_{k}$ and $Z_{i j}$ are vectors of airline and route specific characteristics, respectively.

Data for the dependent variables, scheduled departures per month and seats per departure, are constructed from the Department of Transportation's (DOT) 2005 T-100 service-segment database. Information contained in the T100 is derived from Form 41, which large scheduled carriers ${ }^{4}$ have been required to submit since 1990. Among other information, the form contains numbers of departures and seats by carrier for each non-stop US route segment on a specific plane type in a given month.

Beginning in the third quarter of 2002, the DOT required all air carriers, including small

\footnotetext{
${ }^{4}$ The BTS defines large certificated air carriers as airlines that hold Certificates of Public Convenience and Necessity issued by the U.S. Department of Transportation (DOT) and operate aircraft with seating capacity of more than 60 seats or a maximum payload capacity of more than 18,000 pounds. (http://www.bts.gov/publications/airport_activity_statistics_of_certificated_air_carriers/)
} 
and regional air carriers, to submit data. To assign regional carriers to major airlines, annual 10K reports filed each year with the Securities and Exchange Commission for all the major and regional airlines are analyzed to identify partnerships. Assignments are subsequently checked for accuracy by cross-checking regional carrier route maps and the schedules of their major carrier partners to ensure that the routes are properly assigned. The resulting assignments can be found in Table 2 .

To insure that flights are in fact regularly scheduled, the data is limited to observations where the carrier has more than 20 scheduled departures per month on a specific plane type. All flights in a month by a major airline on a route are then collapsed into a single observation. Thus, an observation in the analysis come from summing flights on a route operated by a major airline and its partners over all plane types in a given month. Summary statistics for the data can be found in Table 3

Data for the explanatory variables come mostly from a variety of government databases, including the 2000 US Census, the DOT's Origin and Destination Survey and On-Time Performance datasets, and the Federal Aviation Administration's National Flight Data Center's Airport Runways Data Table. A brief description of the databases and variable construction follows.

The vector of market demographic data includes the proportion of households with an annual income greater $\$ 75,000$, the percentage of managerial workers (obtained by summing all workers in managerial occupations), and the proportion of population under 25 years of age, as well as total population. As airports serve an area larger than their name implies, airports are matched to a Metropolitan Statistical Area ${ }^{5}$ (MSA), with data for each endpoint

\footnotetext{
${ }^{5}$ A Metropolitan Statistical Area is defined as a core area containing a large population nucleus, together with adjacent communities having a high degree of economic and social integration with that core.
} 
used in the regression, as noted in equation (6). Data come from the 2000 Census, gathered from the 2007 State and Metropolitan databook. The use of MSA data, however, limits the data to city pairs within the contiguous 48 United States. More details on the census data and attribution to an airport can be found in the appendix.

Endpoint airport characteristics data, which include the number of nearby airports, maximum runway length and slot constraints, come from several datasets. Maximum runway length and latitude and longitude are obtained from the Federal Aviation Administration's National Flight Data Center's Airport Runways Data Table. To identify nearby airports, the longitude and latitude is used to calculate the distance between all airports in the US via the great circle formula. The number of airports in the vicinity is then the count of all airports that are within 75 miles of the given endpoint. Slot Constrained is a dummy variable that takes on the value 1 if the origin or destination is New York's JFK or LaGuardia, Chicago O'Hare, or Washington National.

In this study, two variables are used as a proxy for hub airport status: number of destinations served and the proportion of passengers that are connecting to other flights at the airport, each measured at the airline level. The number of destinations served from the endpoint is the sum of destinations served by the carrier derived from the T100. Connecting shares are computed by analyzing the DOT's 2004 DB1B dataset. The DB1B contains, among other things, information on a passenger's origin, destination and routing. To derive connecting shares, individual coupons are analyzed to determine the actual route. Passengers that pass through an airport without a break in their itinerary are determined to be connecting. Both hub proxy variables are computed for the year 2004 to avoid endogeneity.

Airline identity is preserved in the dataset, though individual airline fixed effects are not 
included in the model. When the model was estimated with airline fixed effects, all of the population characteristic variables were rendered insignificant. Airline identities are, however, used to construct several control variables. An LCC dummy takes on the value 1 when the airline is Southwest, Airtran, JetBlue, or ATA. A dummy variable indicating ownership of regional carriers takes on the value 1 when the major owns a regional carrier. In 2005, this criterion was satisfied for American and Delta Airlines. Their owned regional carriers can be found in Table 2 .

Route characteristics include distance between the two endpoints and a leisure variable. The distance between the two endpoints, as used in this study, is reported in the T100 database. Leisure takes on the value 1 when either endpoint is Las Vegas (LAS) or Orlando (MCO).

Finally, the effects of delay and cancellations are considered. Delayed and cancelled flight information is derived from the DOT's on-time database. This database contains, among other items, delay and cancellation data on every flight operated by the major U.S. carriers. To avoid endogeneity, data from the year 2004 are used. Delay is calculated as the sum of the absolute value of arrival and departure delay at the origin and destination, respectively, for the given airline. In this fashion, arriving early is equivalent to arriving late. ${ }^{6}$ Whereas arrival and departure delays are attributable to the origin and destination, the data reports a particular flight as cancelled, without attribution to the source. Cancellations are, therefore, attributed to both the origin and destination. Cancellations, as used in the analysis, are calculated as the percentage of flights the airline cancels at each airport.

Despite the fact that delay and cancellations are lagged and measured at the airport level,

\footnotetext{
${ }^{6}$ This approach can be justified as follows. Suppose a passenger is to picked up at the airport at a predetermined time. If their flight arrives early, the passenger must wait for their greeter, whereas if the flight arrives late, the greeter must wait for the passenger. In essence, either party would be confronted with a waiting cost, and this construction accounts for this cost.
} 
they may still be endogenous to aircraft size and flight frequency on individual routes. Thus, precipitation at the endpoints and aircraft movements per runway are used as instrumental variables in a two-stage least squares regression that treat delays and cancellations as endogeneous. Historic precipitation data is gathered from the U.S. National Oceanic \& Atmospheric Administration (NOAA) website. The number of aircraft movements per runway is derived by dividing the number of takeoffs and landings by the number of runways, as reported in the FAA's Airport Runways Data Table.

\section{Empirical Results}

The results of the regressions with frequency and aircraft size as the dependent variables are presented in Tables 4 and Table 5, respectively. The first column in each table is the base specification. Base-specification results for flight frequency and subsequently aircraft size are now presented, before turning attention to the effect of delay and cancellations.

\subsection{Flight Frequency}

Time of year and population characteristics play a significant role in determining flight frequency. As expected, the second and third quarters, which correspond to the spring and peak summer travel periods, have the highest frequency. The 4th quarter, which is omitted, has the lowest frequency, and the 1st quarter coefficient is statistically insignificant. As population increases, frequency increases, as suggested by the theoretical framework and confirmed by the positive population coefficients. Specifically, an increase of 100,000 people at the origin or destination results in an increase of .73 or .76 flights per month, respectively. Increased household income also causes an increase in frequency, with each percent-point increase in 
households earning more than $\$ 75,000$ resulting in 2.7 additional flights per month.

Of all population characteristics, the proportion of managers in the workforce has the largest effect. An additional percentage-point of managers in the workforce at the origin or destination results in nearly an additional flight per day, or approximately 20 or 24 flights per month, respectively. The higher frequencies for routes with high incomes and many managers suggest that airlines are attentive to schedule delay, as suggested by the theoretical framework. Finally, an increase in the proportion of the population below 25 years of age leads to a slight increase in flight frequency. This effect may indicate that families with young children and college students travel more than older people.

The presence of vicinity airports, among other airport characteristics, has a major impact on flight frequency. As can be seen, each additional airport within a 75 mile radius results in approximately 9 fewer flights per month. The presence of additional airports would split the metropolitan area's traffic, resulting in lower frequency at each airport. In addition, more airports in an area may lead to additional airspace congestion, and therefore result in lower flight frequency. For example, in the New York City area, with 3 major airports and several smaller ones, airspace coordination is a major problem. Runway length also positively affects flight frequency, though its effect may be more indirect. Airports with long runways also tend to have more runways, and are thus capable of having more aircraft movements.

Hubs are associated with greater frequency. One additional destination results in an additional .6 flights per month. A one percent increase in the share of connecting passengers leads to an increase of 27 and 16 flights per month at the origin and destination, respectively. Finally, low cost carriers have greater frequency than non-low cost carriers.

Distance plays a major role in determining flight frequency. Every 1000 mile increase in 
distance results in 62 fewer flights over the course of a month, or 2 fewer flights per day. There are two explanations for this trend. As the distance between the two endpoints increases, planes can make fewer trips over the course of a day. In addition, as distance increases, the chance that a hub city is on the flight path increases. Unless a compelling factor exists, ${ }^{7}$ an airline might opt to route the flight through the hub. Leisure routes have greater frequency, with an increase of more than 1 flight per day if the route involves Las Vegas or Orlando.

The second specification in Table 4 adds slot constraints and major ownership of regional carriers. As can be seen, the presence of a slot-constrained airport on the route results in a drop of nearly one flight day compared to routes without such airports. This finding is consistent with the rationale for slot constraints, namely, that there should be fewer flights. Major ownership of a regional carrier results in nearly an additional flight per day. Forbes and Lederman (2005) suggest regional ownership allows major carriers to mitigate problems that arise when unforeseen schedule disruptions occur. Thus, the ability to mitigate problems, should they arise, allows airlines greater flexibility, and as shown, results in greater frequency.

\subsection{Aircraft Size}

Attention now turns to aircraft size, as measured by seats per departure. Time of year and population characteristics play a significant role in determining aircraft size. As compared to the omitted 4th quarter, all quarters have larger aircraft sizes, with the 1st and 2nd quarter having the largest sizes. Consistent with the theoretical model, aircraft size increases as population increases. An increase of 100,000 people at the origin or destination results in an additional .09 or .07 seats per departure, respectively. The small size of this effect suggests that

\footnotetext{
${ }^{7}$ Brueckner and Pai (2007) explore the determinants of point-to-point service.
} 
higher travel demands are met mainly through greater frequency. An increase in household income in an area also results in larger aircraft size: 1 or .8 more seats for every percent increase in households earning more than $\$ 75,000$ at the origin or destination, respectively. An increased share of managerial workers, however, results in a decrease of approximately 1.5 seats per departure. Coupled with the fact that airlines increase frequency as the share of managerial workers increases, this finding indicates that airlines use smaller airplanes and have higher frequency on routes between endpoints with a large share of managers. A higher youth proportion also results in a decrease in plane size.

Airport characteristics play a large role in determining aircraft size. Runway length is often a constraint on aircraft size. Larger planes require longer runways to take off and land, and this connection is confirmed by the positive relationship between size and runway length. An additional 1000 feet of runway results in an increase of 1.54 or 1.38 seats per departure at the origin or destination, respectively. The presence of nearby airports leads to a decrease in aircraft size. As with frequency, this effect is expected, as multiple airports would split the passenger pool over all airports in the area. In order to keep planes full, airlines would utilize smaller aircraft with lower frequency at each airport in a multiple-airport metro area.

Airlines utilize larger planes on routes that involve hubs. As can been seen from the coefficients on the hub variables, a one percentage point increase in connecting share results in nearly a 7 seat per departure increase in aircraft size. In contrast, service to an additional destination increases aircraft size by less than one quarter of a seat. As expected, low cost carriers have more seats per departure. In addition to serving larger areas, low cost carriers often have a single aircraft type, usually in the 120-140 passenger range. This contrasts with network carriers, which utilize multiple plane types that range from 30-300+ seats. 
Finally, distance is a major factor in plane size decisions, as shown by both Bhadra (2005) and Givoni and Rietveld (2006). As the distance between the two endpoints increases, longerrange (and thus larger) aircraft are needed. This effect is confirmed by the positive relationship between distance and seats per departure. A 1000 mile increase in distance between the endpoints results in an increase of nearly 30 seats per departure. Leisure routes also have larger aircraft, with an increase of more than 15 seats if the route involves Las Vegas or Orlando.

The second specification in Table 5 adds slot constraints and major ownership of regional carriers to the model. As can be seen, the presence of a slot constrained airport on the route results in a small drop in seats per departure, though this coefficient is statistically insignificant. Dresner et al. (2002b) find that slot controls, gate constraints (due to exclusive leasing arrangements between airlines and airports), and gate utilization during peak periods all contribute to airline yields. Thus, airlines have an incentive to prevent their excess slot and gate capacity from being used by their competitors. By utilizing smaller aircraft, airlines are able to hold their slots and gates, while limiting capacity (and as a consequence, not having to reduce prices due to competition.)

Major ownership of regional carriers results in a 1.74 decrease in seats per departure. This finding suggests that majors that own regional carriers have greater flexibility in utilizing smaller aircraft. Pilot unions often limit the use of various plane sizes through "scope clauses," which limit the use of of small aircraft. Presumably, carriers that own regional subsidiaries have greater flexibility in deploying aircraft of various sizes on routes than carriers that do not own regional subsidiaries. 


\subsection{Summary}

The preceding results are summarized as follows. Frequency and aircraft size increase with population and income. An increase in the proportion of managers in the workforce and in the share of population below 25 years of age results in greater frequency and the use of smaller planes. An increase in runway length results in higher frequency and larger plane sizes. Routes on which airports are slot constrained and have more competing airports nearby have lower flight frequency and smaller planes. Hubs and low cost carriers are associated with larger plane sizes and higher frequency, and regional-airline ownership leads to higher frequency and the use of smaller planes. An increase in distance between the endpoints leads to lower frequency and the use of larger planes. The implications of delay and cancellations on aircraft choice and flight frequency are discussed in the next section.

\subsection{Impact of Delay and Cancellations}

Delay and cancellations on a route often result in disruptions throughout the airline's network. Thus, in order to minimize schedule disruptions, airlines may have an incentive to provide lower frequency on routes that are delay and cancellation-prone. This section analyzes the effect of delays on flight frequency and subsequently aircraft size, before turning attention to the effect of cancellations on frequency and aircraft size.

Delays impact flight frequency. As can be seen in Table 6, column (a), a one minute increase in delay at the origin or destination airport results in a .28 or .15 decrease in the number of flights per month, respectively. Given the possible simultaneity between delay and the dependent variable, a two-stage least squares model was also estimated using precipitation and aircraft movements per runway as instruments for delay. As shown in Table 6, column (b), 
qualitative results are the same under the 2SLS specification, although the magnitude of the delay effect rises to a 2 flight per month decrease in frequency. Thus, it appears that airlines are trying to limit disruptions to their schedule by reducing frequency at delay-prone airports.

Like frequency, aircraft size is impacted by delay. As can been seen in Table 6, column (c), a one minute increase in average delay results in nearly a one-quarter seat per departure decrease in plane size. One plausible explanation is that short-haul routes are more likely to be delayed, and that short routes are, in-turn, serviced by small planes. As in the frequency case, a 2SLS regression was estimated using precipitation and aircraft movements per runway as instruments for delay at the airport level. The qualitative results of the 2SLS specification are similar to the OLS results, though the magnitude of the delay effect decreases to 1.6 or .47 seats per departure at the origin or destination, respectively.

Cancellations play a significant role in the flight frequency decision. As can been seen in Table 7, column (a), an increase in the share of cancelled flights at the route endpoints results in greater frequency. While this finding appears counterintuitive from an operations standpoint, it makes sense. Recall that the cancellation data is lagged relative to the frequency variable. Thus, in response to past cancellations, airlines are scheduling more flights, and the reason appears to be that greater flight frequency allows airlines to cancel a flight without causing passengers significant inconvenience. In addition, as suggested by Rupp (2005), airlines may choose to not cancel infrequent flights in order to maintain their schedules following the cancellation. Additional frequency allows an airline to cancel flights without major schedule disruptions.

Cancellations also influence aircraft size. As shown in Table 7, column (c), cancellations lead to larger aircraft size. The apparent explanation is that, if an airline is likely to cancel 
a flight, additional capacity on the remaining flights is necessary to service all its passengers. These findings suggest that airlines use both frequency and aircraft size to hedge against cancellations.

Using precipitation and aircraft movements per runway as instruments for cancellation, the 2SLS results are similar to the OLS results: airlines provide higher frequency and use larger planes on routes with cancellation-prone endpoints. Note the statistical insignificance of the coefficients on many of the population characteristics and the share of connecting passengers in Table 7, column (d). This outcome suggests that the instruments capture some of the heterogeneity previously captured by managerial share of the workforce and the connecting share.

\section{Conclusion}

The US airline industry has experienced rampant delays, and expectations are that the delay problem will become more severe. Airlines are utilizing smaller planes with greater frequency, while the government is relying on an air traffic control system that was not meant for handling the number of flights being flown. This paper explores the factors that might lead airlines to exacerbate the problems of over-utilized infrastructure by examining the determinants of aircraft sizes and the frequency of flights between airports.

The paper shows that frequency and aircraft size increase with population and income. An increase in the share of managerial workers or the proportion of the population below 25 years of age results in greater frequency and the use of smaller planes. An increase in runway length results in higher frequency and larger plane sizes. Slot constrained airports and an increase in nearby airports lead to lower flight frequency and smaller planes. Hub airports and 
low cost carriers are associated with larger plane sizes and higher frequency, though major airline ownership of regional carriers leads to higher frequency and the use of smaller planes. An increase in distance between the endpoints leads to lower frequency and the use of larger planes. An increase in delay at the route endpoints leads to lower frequency and smaller planes. An increase in cancellations, however, leads to higher frequency and the use of larger planes. These findings suggest that airlines utilize frequency and aircraft size to hedge against flight cancellations, and it warrants further exploration.

Various proposals have been suggested to ease delays at US airports. In the past, government officials have asked airlines to voluntarily reduce frequency during peak periods to cut congestion. By exposing the determinants of flight frequency, however, the results in this paper show the pitfalls in this kind of bureaucratic approach. In particular, the paper's findings show that high frequencies represent the airlines' response to the demand for convenient service by time sensitive passengers, who have high incomes or managerial jobs. Arbitrary frequency restrictions prevent the fulfillment of these demands in a efficient manner. A better approach would be to adopt congestion pricing, which would allow time sensitive passengers to be served at times of their choosing if they are willing to pay higher fares, which would embody the congestion charges for peak-hour travel. 
Figure 1: Network Configuration

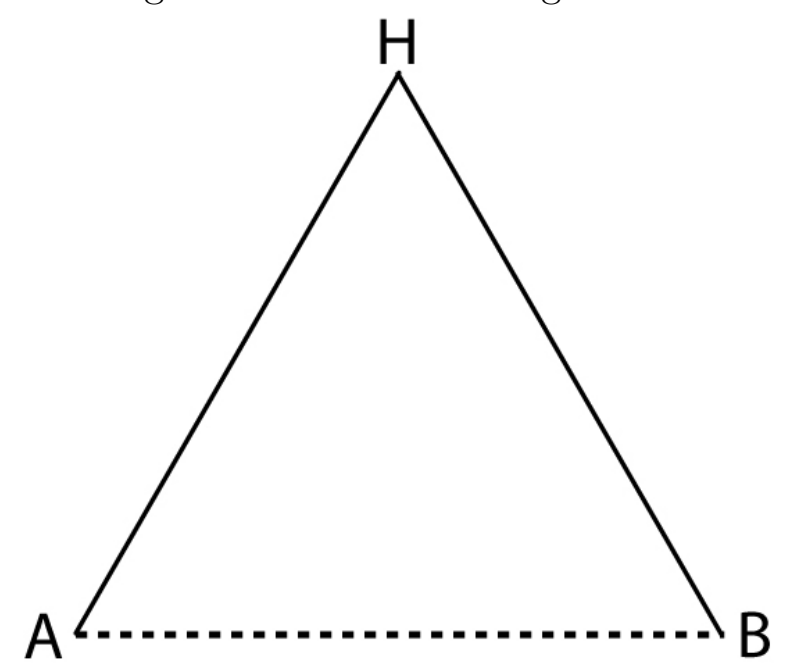

Table 1: Average Demographic Characteristics for Cities with and without LCC Service

\begin{tabular}{lrr}
\hline \hline & Without LCC service & With LCC service \\
\hline Population & 291,124 & $2,365,669$ \\
Household income over 75k & $16.86 \%$ & $23.78 \%$ \\
Percent Managers & $33.78 \%$ & $46.70 \%$ \\
Percent Young & $36.51 \%$ & $35.11 \%$ \\
\hline
\end{tabular}


Table 2: Regional Carrier Assignment

\begin{tabular}{|c|c|}
\hline Major Carrier & Regional Carrier \\
\hline \multirow[t]{5}{*}{ American (AA) } & American Eagle* \\
\hline & Executive Airlines* \\
\hline & Regions Air \\
\hline & Chautauqua Airlines \\
\hline & Trans States \\
\hline Alaska (AS) & Horizon* \\
\hline \multirow[t]{4}{*}{ Continental $(\mathrm{CO})$} & ExpressJet \\
\hline & Commutair \\
\hline & Colgan \\
\hline & Skywest \\
\hline \multirow[t]{6}{*}{ Delta (DL) } & ASA/Atlantic Southeast Airlines* \\
\hline & Comair* \\
\hline & Skywest \\
\hline & Chautauqua Airlines $^{a}$ \\
\hline & Republic \\
\hline & Freedom $^{b}$ \\
\hline \multirow[t]{2}{*}{ Northwest (NW) } & Mesaba Airlines \\
\hline & Express Airlines \\
\hline \multirow[t]{8}{*}{ United (UA) } & Air Wiconsin ${ }^{c}$ \\
\hline & GoJet \\
\hline & Shuttle America \\
\hline & Trans States \\
\hline & Skywest $^{d}$ \\
\hline & Mesa \\
\hline & Chautauqua Airlines \\
\hline & Colgan $^{e}$ \\
\hline \multirow[t]{3}{*}{ US Airways ${ }^{f}$} & Air Wisconsin \\
\hline & Chautauqua Airlines \\
\hline & Mesa \\
\hline
\end{tabular}

Airlines that serve multiple airlines are assigned based on hub identities, as noted in bold in Table 8. Asterisks indicate major owned regional.

${ }^{a}$ Only routes involving cities in Florida and Raleigh-Durham (RDU)

${ }^{b}$ Only routes involving Orlando, FL (MCO)

${ }^{c}$ Only on routes involving Chicago O'hare (ORD) and Washington Dulles (IAD)

${ }^{d}$ Including routes involving Portland, OR (PDX), Medford, OR (MFR), and Eureka-Arcata, CA (ACV)

${ }^{e}$ Only routes involving Washington Dulles (IAD)

${ }^{f}$ The following airlines, which are observed in the T100 database, are also assigned to US Airways: PSA Airlines, Piedmont, and America West 
Table 3: Summary Statistics

\begin{tabular}{lr}
\hline \hline Variables & Means \\
\hline & \\
Time Control Variables & \\
1st Quarter & .242 \\
2nd Quarter & .250 \\
3rd Quarter & .256 \\
& \\
Population Characteristics & 38.637 \\
Origin Population (in hundred thousands) & 39.426 \\
Destination Population (in hundred thousands) & 26.273 \\
Origin Income above \$75,000 & 26.529 \\
Destination Income above $\$ 75,000$ & 0.427 \\
Origin Percent Managers & 0.425 \\
Destination Percent Managers & 35.107 \\
Origin Percent Young & 35.095 \\
Destination Percent Young & \\
& \\
Airport Characteristics & 10.912 \\
Origin Maximum Runway Length & 11.027 \\
Destination Maximum Runway Length & 2.259 \\
Vicinity Airports near Origin & 2.272 \\
Vicinity Airports near Destination & 29.570 \\
Delay at Origin (in minutes) & 29.583 \\
Delay at Destination (in minutes) & 7031.54 \\
Operations per runway at Origin & 7288.53 \\
Operations per runway at Destination & 2.983 \\
Precipitation at Origin (in inches) & 2.981 \\
Precipitation at Destination (in inches) & \\
Airline Characteristics & 0.073 .475 \\
Number of Destinations from Origin & 0.190 \\
Number of Destinations from Destination & 0.229 \\
Share of Connecting Passengers at Origin & 0.327 \\
Share of Connecting Passengers at Destination & \\
Low Cost Carrier & \\
Major Carrier owns Regional Carrier & \\
& \\
Route Characteristics & \\
Distance (in thousands of feet) & \\
Leisure Route & \\
Aircraft Size & \\
Frequency & \\
Average Delay & \\
Cancelled Flights & \\
\hline
\end{tabular}


Table 4: Frequency

\begin{tabular}{|c|c|c|}
\hline \multirow{2}{*}{$\begin{array}{l}\text { Dependent Variable } \\
\text { Intercept }\end{array}$} & \multicolumn{2}{|c|}{ Departures Scheduled } \\
\hline & $\begin{array}{c}-164.7^{*} \\
(8.564)\end{array}$ & $\begin{array}{c}-155.3^{*} \\
(8.45)\end{array}$ \\
\hline \multicolumn{3}{|l|}{ Time Control Variables } \\
\hline 1st Quarter & $\begin{array}{l}1.315 \\
(1.016)\end{array}$ & $\begin{array}{c}1.365 \\
(1.001)\end{array}$ \\
\hline 2nd Quarter & $\begin{array}{l}5.489^{*} \\
(1.005)\end{array}$ & $\begin{array}{l}5.603^{*} \\
(0.991)\end{array}$ \\
\hline 3rd Quarter & $\begin{array}{l}6.140^{*} \\
(0.998)\end{array}$ & $\begin{array}{l}6.001^{*} \\
(0.986)\end{array}$ \\
\hline \multicolumn{3}{|l|}{ Population Characteristics } \\
\hline Origin Population & $\begin{array}{l}0.732^{*} \\
(0.016)\end{array}$ & $\begin{array}{l}0.771^{*} \\
(0.016)\end{array}$ \\
\hline Destination Population & $\begin{array}{l}0.763^{*} \\
(0.083)\end{array}$ & $\begin{array}{l}0.793^{*} \\
(0.016)\end{array}$ \\
\hline Origin Income above $\$ 75,000$ & $\begin{array}{l}2.794 \\
(0.080)\end{array}$ & $\begin{array}{l}3.049^{*} \\
(0.079)\end{array}$ \\
\hline Destination Income above $\$ 75,000$ & $\begin{array}{l}2.784 \\
(0.083)\end{array}$ & $\begin{array}{l}2.979^{*} \\
(0.082)\end{array}$ \\
\hline Origin Percent Managers & $\begin{array}{c}19.798^{*} \\
(1.331)\end{array}$ & $\begin{array}{c}17.249^{*} \\
(1.316)\end{array}$ \\
\hline Destination Percent Managers & $\begin{array}{c}24.362^{*} \\
(1.494)\end{array}$ & $\begin{array}{c}21.574^{*} \\
(1.479)\end{array}$ \\
\hline Origin Percent Young & $\begin{array}{l}0.753^{*} \\
(0.151)\end{array}$ & $\begin{array}{l}0.413^{*} \\
(0.149)\end{array}$ \\
\hline Destination Percent Young & $\begin{array}{l}0.794 \\
(0.154)\end{array}$ & $\begin{array}{l}0.465^{*} \\
(0.152)\end{array}$ \\
\hline \multicolumn{3}{|l|}{ Airport Characteristics } \\
\hline Origin Maximum Runway Length & $\begin{array}{l}0.996^{*} \\
(0.205)\end{array}$ & $\begin{array}{l}0.840^{*} \\
(0.201)\end{array}$ \\
\hline Destination Maximum Runway Length & $\begin{array}{l}1.218 \\
(0.202)\end{array}$ & $\begin{array}{l}1.126^{*} \\
(0.199)\end{array}$ \\
\hline Slot Constraints & & $\begin{array}{c}-19.269^{*} \\
(1.13)\end{array}$ \\
\hline Vicinity Airports near Origin & $\begin{array}{c}-9.765^{*} \\
(0.320)\end{array}$ & $\begin{array}{c}-9.293^{*} \\
(0.317)\end{array}$ \\
\hline Vicinity Airports near Destination & $\begin{array}{c}-8.883^{*} \\
(0.314)\end{array}$ & $\begin{array}{c}-8.697^{*} \\
(0.310)\end{array}$ \\
\hline \multicolumn{3}{|l|}{$\underline{\text { Airline Characteristics }}$} \\
\hline$\overline{\text { Number of Destinations from Origin }}$ & $\begin{array}{c}0.668^{*} \\
(0.020)\end{array}$ & $\begin{array}{l}0.590^{*} \\
(0.020)\end{array}$ \\
\hline Number of Destinations from Destination & $\begin{array}{l}0.612 \\
(0.020)\end{array}$ & $\begin{array}{l}0.543^{*} \\
(0.020)\end{array}$ \\
\hline Share of Connecting Passengers at Origin & $\begin{array}{c}27.116^{*} \\
(4.567)\end{array}$ & $\begin{array}{c}38.155^{*} \\
(4.566)\end{array}$ \\
\hline Share of Connecting Passengers at Destination & $\begin{array}{l}16.243^{*} \\
(4.572)\end{array}$ & $\begin{array}{c}28.146^{*} \\
(4.522)\end{array}$ \\
\hline Low Cost Carrier & $\begin{array}{l}46.102^{*} \\
(1.119)\end{array}$ & $\begin{array}{c}53.644^{*} \\
(1.133)\end{array}$ \\
\hline Major Carrier owns Regional Carrier & & $\begin{array}{c}28.297^{*} \\
(0.835)\end{array}$ \\
\hline \multicolumn{3}{|l|}{ Route Characteristics } \\
\hline Distance & $\begin{array}{c}-62.011^{*} \\
(0.671)\end{array}$ & $\begin{array}{c}-62.286^{*} \\
(0.665)\end{array}$ \\
\hline Leisure Route & $\begin{array}{l}31.977^{*} \\
(1.491)\end{array}$ & $\begin{array}{c}35.062^{*} \\
(1.471)\end{array}$ \\
\hline Observations & 41,357 & 41,357 \\
\hline$R^{2}$ & 0.3196 & 0.3398 \\
\hline $\operatorname{Adj} R^{2}$ & 0.3193 & 0.3394 \\
\hline
\end{tabular}

Standard errors in parentheses. ${ }^{*}$ significant at $1 \%$ level; 
Table 5: Aircraft Size

\begin{tabular}{|c|c|c|}
\hline \multirow{2}{*}{$\begin{array}{l}\text { Dependent Variable } \\
\text { Intercept }\end{array}$} & \multicolumn{2}{|c|}{ Seats per Departure } \\
\hline & ${ }_{(4.265)}^{113.501^{*}}$ & $\begin{array}{c}112.438^{*} \\
(4.272)\end{array}$ \\
\hline \multicolumn{3}{|l|}{ Time Control Variables } \\
\hline 1st Quarter & $\begin{array}{c}2.916 * \\
(0.506)\end{array}$ & $\begin{array}{l}2.891^{*} \\
(0.506)\end{array}$ \\
\hline 2nd Quarter & $\begin{array}{l}2.718^{*} \\
(0.501)\end{array}$ & $\begin{array}{l}2.691^{*} \\
(0.501)\end{array}$ \\
\hline 3rd Quarter & $\begin{array}{c}1.169^{* *} \\
(0.498)\end{array}$ & $\begin{array}{c}1.162^{* *} \\
(0.498)\end{array}$ \\
\hline \multicolumn{3}{|l|}{ Population Characteristics } \\
\hline Origin Population & $\begin{array}{l}0.087^{*} \\
(0.008)\end{array}$ & $\begin{array}{l}0.089^{*} \\
(0.008)\end{array}$ \\
\hline Destination Population & $\begin{array}{c}0.065^{*} \\
(0.008)\end{array}$ & $\begin{array}{l}0.066 \\
(0.008)\end{array}$ \\
\hline Origin Income above $\$ 75,000$ & $\begin{array}{l}1.031^{*} \\
(0.040)\end{array}$ & $\begin{array}{l}1.035^{*} \\
(0.040)\end{array}$ \\
\hline Destination Income above $\$ 75,000$ & $\begin{array}{c}0.790^{*} \\
(0.041)\end{array}$ & $\begin{array}{l}0.789^{*} \\
(0.042)\end{array}$ \\
\hline Origin Percent Managers & $\begin{array}{c}-1.486^{*} \\
(0.663)\end{array}$ & $\begin{array}{c}-1.495^{*} \\
(0.665)\end{array}$ \\
\hline Destination Percent Managers & $\begin{array}{c}-1.617^{*} \\
(0.744)\end{array}$ & $\begin{array}{c}-1.664^{*} \\
(0.747)\end{array}$ \\
\hline Origin Percent Young & $\begin{array}{c}-1.898^{*} \\
(0.075)\end{array}$ & $\begin{array}{c}-1.877^{*} \\
(0.075)\end{array}$ \\
\hline Destination Percent Young & $\begin{array}{c}-1.728^{*} \\
(0.076)\end{array}$ & $\begin{array}{c}-1.707^{*} \\
(0.077)\end{array}$ \\
\hline \multicolumn{3}{|l|}{ Airport Characteristics } \\
\hline Origin Maximum Runway Length & $\begin{array}{l}1.541^{*} \\
(0.102)\end{array}$ & $\begin{array}{l}1.559^{*} \\
(0.102)\end{array}$ \\
\hline Destination Maximum Runway Length & $\begin{array}{l}1.378^{*} \\
(0.100)\end{array}$ & $\begin{array}{l}1.390^{*} \\
(0.100)\end{array}$ \\
\hline Slot Constraints & & $\begin{array}{c}-0.541 \\
(0.569)\end{array}$ \\
\hline Vicinity Airports near Origin & $\begin{array}{c}-2.131^{*} \\
(0.160)\end{array}$ & $\begin{array}{c}-2.121^{*} \\
(0.160)\end{array}$ \\
\hline Vicinity Airports near Destination & $\begin{array}{c}-2.950^{*} \\
(0 . .156)\end{array}$ & $\begin{array}{c}-2.931^{*} \\
(0 . .157)\end{array}$ \\
\hline \multicolumn{3}{|l|}{ Airline Characteristics } \\
\hline Number of Destinations from Origin & $\begin{array}{c}0.186^{*} \\
(0.010)\end{array}$ & $\begin{array}{l}0.191^{*} \\
(0.010)\end{array}$ \\
\hline Number of Destinations from Destination & $\begin{array}{l}0.201^{*} \\
(0.010)\end{array}$ & $\begin{array}{l}0.206^{*} \\
(0.010)\end{array}$ \\
\hline Share of Connecting Passengers at Origin & $\begin{array}{l}7.410^{*} \\
(2.300)\end{array}$ & $\begin{array}{l}6.541^{*} \\
(2.308)\end{array}$ \\
\hline Share of Connecting Passengers at Destination & $\begin{array}{l}6.976^{*} \\
(2.277)\end{array}$ & $\begin{array}{l}6.062^{*} \\
(2.286)\end{array}$ \\
\hline Low Cost Carrier & $\begin{array}{c}40.778^{*} \\
(0.557)\end{array}$ & $\begin{array}{c}40.070^{*} \\
(0.573)\end{array}$ \\
\hline Major Carrier owns Regional Carrier & & $\begin{array}{c}-1.738^{*} \\
(0.424)\end{array}$ \\
\hline \multicolumn{3}{|l|}{$\underline{\text { Route Characteristics }}$} \\
\hline Distance & $\begin{array}{c}30.096^{*} \\
(0.334)\end{array}$ & $\begin{array}{c}30.002^{*} \\
(0.336)\end{array}$ \\
\hline Leisure Route & $\begin{array}{c}15.415^{*} \\
(0.742)\end{array}$ & $\begin{array}{c}15.242^{*} \\
(0.743)\end{array}$ \\
\hline Observations & 41,353 & 41,353 \\
\hline$R^{2}$ & 0.3742 & 0.3745 \\
\hline $\operatorname{Adj} R^{2}$ & 0.3739 & 0.3742 \\
\hline
\end{tabular}

Standard errors in parentheses. ${ }^{*}$ significant at $1 \%$ level;

** significant at $5 \%$ level 
Table 6: Frequency and Aircraft Size with Delay

\begin{tabular}{|c|c|c|c|c|}
\hline \multirow{2}{*}{$\begin{array}{l}\text { Dependent Variable } \\
\text { Estimation Method }\end{array}$} & \multicolumn{2}{|c|}{ Depatures Scheduled } & \multicolumn{2}{|c|}{ Seats per Departure } \\
\hline & OLS & $2 \mathrm{SLS}$ & OLS & 2SLS \\
\hline & (a) & (b) & (c) & (d) \\
\hline Intercept & $\begin{array}{c}-148.87^{*} \\
(8.616)\end{array}$ & $\begin{array}{c}-231.34^{*} \\
(12.583)\end{array}$ & $\begin{array}{l}123.8^{*} \\
(4.275)\end{array}$ & $\begin{array}{l}44.4^{*} \\
(7.013)\end{array}$ \\
\hline \multicolumn{5}{|l|}{ Time Control Variables } \\
\hline 1st Quarter & $\begin{array}{c}0.619 \\
(1.017)\end{array}$ & $\begin{array}{l}5.880^{*} \\
(1.274)\end{array}$ & $\begin{array}{l}2.329^{*} \\
(0.505)\end{array}$ & $\begin{array}{l}6.783^{*} \\
(0.710)\end{array}$ \\
\hline 2nd Quarter & $\begin{array}{l}5.732^{*} \\
(1.003)\end{array}$ & $\begin{array}{l}3.840^{*} \\
(1.219)\end{array}$ & $\begin{array}{l}2.873^{*} \\
(0.499)\end{array}$ & $\begin{array}{l}2.403^{*} \\
(0.679)\end{array}$ \\
\hline 3rd Quarter & $\begin{array}{l}5.924^{*} \\
(0.999)\end{array}$ & $\begin{array}{l}8.726^{*} \\
(1.225)\end{array}$ & $\begin{array}{c}0.948^{* *} \\
(0.496)\end{array}$ & $\begin{array}{l}2.993^{*} \\
(0.683)\end{array}$ \\
\hline \multicolumn{5}{|l|}{ Population Characteristics } \\
\hline Origin Population & $\begin{array}{l}0.751^{*} \\
(0.016)\end{array}$ & $\begin{array}{l}0.536^{*} \\
(0.026)\end{array}$ & $\begin{array}{l}0.102^{*} \\
(0.007)\end{array}$ & $\begin{array}{l}0.422^{*} \\
(0.014)\end{array}$ \\
\hline Destination Population & $\begin{array}{l}0.781^{*} \\
(0.016)\end{array}$ & $\begin{array}{l}0.533^{*} \\
(0.026)\end{array}$ & $\begin{array}{l}0.078^{*} \\
(0.008)\end{array}$ & $\begin{array}{l}0.344^{*} \\
(0.014)\end{array}$ \\
\hline Origin Income above $\$ 75,000$ & $\begin{array}{l}2.814^{*} \\
(0.080)\end{array}$ & $\begin{array}{l}2.849^{*} \\
(0.095)\end{array}$ & $\begin{array}{l}1.033^{*} \\
(0.040)\end{array}$ & $\begin{array}{l}1.036^{*} \\
(0.053)\end{array}$ \\
\hline Destination Income above $\$ 75,000$ & $\begin{array}{l}2.765^{*} \\
(0.083)\end{array}$ & $\begin{array}{l}2.700^{*} \\
(0.099)\end{array}$ & $\begin{array}{l}0.791^{*} \\
(0.041)\end{array}$ & $\begin{array}{l}0.731^{*} \\
(0.055)\end{array}$ \\
\hline Origin Percent Managers & $\begin{array}{c}19.104^{*} \\
(1.332)\end{array}$ & $\begin{array}{c}23.521^{*} \\
(1.739)\end{array}$ & $\begin{array}{c}-2.051^{*} \\
(0.661)\end{array}$ & $\begin{array}{c}1.691^{* *} \\
(0.968)\end{array}$ \\
\hline Destination Percent Managers & $\begin{array}{c}24.160^{*} \\
(1.509)\end{array}$ & $\begin{array}{c}27.135^{*} \\
(2.127)\end{array}$ & $\begin{array}{c}-2.425^{*} \\
(0.749)\end{array}$ & $\begin{array}{l}3.468^{*} \\
(1.185)\end{array}$ \\
\hline Origin Percent Young & $\begin{array}{l}0.677^{*} \\
(0.151)\end{array}$ & $\begin{array}{l}0.926^{*} \\
(0.188)\end{array}$ & $\begin{array}{c}-1.948^{*} \\
(0.075)\end{array}$ & $\begin{array}{c}-1.523^{*} \\
(0.105)\end{array}$ \\
\hline Destination Percent Young & $\begin{array}{l}0.729^{*} \\
(0.153)\end{array}$ & $\begin{array}{c}1.049 * * \\
(0.191)\end{array}$ & $\begin{array}{c}-1.782^{*} \\
(0.076)\end{array}$ & $\begin{array}{c}-1.379^{*} \\
(0.106)\end{array}$ \\
\hline \multicolumn{5}{|l|}{ Airport Characteristics } \\
\hline Origin Maximum Runway Length & $\begin{array}{l}1.120^{*} \\
(0.205)\end{array}$ & $\begin{array}{l}0.645^{*} \\
(0.247)\end{array}$ & $\begin{array}{l}1.662^{*} \\
(0.102)\end{array}$ & $\begin{array}{l}1.081^{*} \\
(0.154)\end{array}$ \\
\hline Destination Maximum Runway Length & $\begin{array}{l}1.321^{*} \\
(0.202)\end{array}$ & $\begin{array}{l}0.191 \\
(0.247)\end{array}$ & $\begin{array}{l}1.476^{*} \\
(0.100)\end{array}$ & $\begin{array}{l}1.146^{*} \\
(0.153)\end{array}$ \\
\hline Vicinity Airports near Origin & $\begin{array}{c}-9.650^{*} \\
(0.324)\end{array}$ & $\begin{array}{l}-8.502^{*} \\
(0.625)\end{array}$ & $\begin{array}{c}-1.989^{*} \\
(0.161)\end{array}$ & $\begin{array}{c}-3.144^{*} \\
(0.348)\end{array}$ \\
\hline Vicinity Airports near Destination & $\begin{array}{c}-8.756^{*} \\
(0.317)\end{array}$ & $\begin{array}{c}-8.996^{*} \\
(0.578)\end{array}$ & $\begin{array}{c}-2.824^{*} \\
(0.157)\end{array}$ & $\begin{array}{c}-3.609^{*} \\
(0.322)\end{array}$ \\
\hline Delay at Origin & $\begin{array}{c}-0.282^{*} \\
(0.098)\end{array}$ & $\begin{array}{c}-2.064^{*} \\
(0.888)\end{array}$ & $\begin{array}{c}-0.216^{*} \\
(0.049)\end{array}$ & $\begin{array}{c}-1.602^{*} \\
(0.495)\end{array}$ \\
\hline Delay at Destination & $\begin{array}{l}-0.147 \\
(0.098)\end{array}$ & $\begin{array}{c}-3.100^{*} \\
(0.870)\end{array}$ & $\begin{array}{c}-0.127^{*} \\
(0.049)\end{array}$ & $\begin{array}{l}-0.473 \\
(0.484)\end{array}$ \\
\hline \multicolumn{5}{|l|}{$\underline{\text { Airline Characteristics }}$} \\
\hline 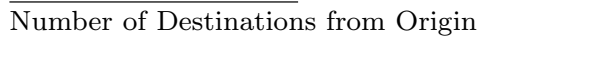 & $\begin{array}{l}0.695^{*} \\
(0.020)\end{array}$ & $\begin{array}{r}0.425^{*} \\
(0.028)\end{array}$ & $\begin{array}{l}0.206^{*} \\
(0.010)\end{array}$ & $\begin{array}{l}0.082^{*} \\
(0.015)\end{array}$ \\
\hline Number of Destinations from Destination & $\begin{array}{l}0.635^{*} \\
(0.020)\end{array}$ & $\begin{array}{l}0.346^{*} \\
(0.027)\end{array}$ & $\begin{array}{c}0.218^{*} \\
(0.010)\end{array}$ & $\begin{array}{l}0.126^{*} \\
(0.015)\end{array}$ \\
\hline Share of Connecting Passengers at Origin & $\begin{array}{c}23.764^{*} \\
(4.623)\end{array}$ & $\begin{array}{c}52.951^{*} \\
(5.904)\end{array}$ & $\begin{array}{c}4.731^{* *} \\
(2.294)\end{array}$ & $\begin{array}{l}15.864 \\
(3.291)\end{array}$ \\
\hline Share of Connecting Passengers at Destination & $\begin{array}{c}11.851^{*} \\
(4.580)\end{array}$ & $\begin{array}{c}38.064^{*} \\
(5.933)\end{array}$ & $\begin{array}{c}3.649^{* * *} \\
(2.273)\end{array}$ & $\begin{array}{l}20.479 \\
(3.307)\end{array}$ \\
\hline Low Cost Carrier & $\begin{array}{c}45.830^{*} \\
(1.118)\end{array}$ & $\begin{array}{c}43.996^{*} \\
(1.308)\end{array}$ & $\begin{array}{c}40.439 * \\
(0.555)\end{array}$ & $\begin{array}{c}41.503^{*} \\
(0.729)\end{array}$ \\
\hline \multicolumn{5}{|l|}{$\underline{\text { Route Characteristics }}$} \\
\hline Distance & $\begin{array}{c}-62.293^{*} \\
(0.670)\end{array}$ & $\begin{array}{c}-58.949^{*} \\
(0.814)\end{array}$ & $\begin{array}{c}29.862^{*} \\
(0.333)\end{array}$ & $\begin{array}{c}32.351^{*} \\
(0.454)\end{array}$ \\
\hline Leisure Route & $\begin{array}{c}32.659^{*} \\
(1.490)\end{array}$ & $\begin{array}{c}30.690^{*} \\
(1.790)\end{array}$ & $\begin{array}{c}15.845^{*} \\
(0.739)\end{array}$ & ${ }_{(0.997)}^{11.881^{*}}$ \\
\hline Observations & 41,353 & & 41,353 & \\
\hline$R^{2}$ & 0.3228 & 0.2602 & 0.3803 & .319 \\
\hline $\operatorname{Adj} R^{2}$ & 0.3224 & 0.2597 & 0.3799 & .318 \\
\hline
\end{tabular}


Table 7: Frequency and Aircraft Size with Cancellations

\begin{tabular}{|c|c|c|c|c|}
\hline \multirow{2}{*}{$\begin{array}{l}\text { Dependent Variable } \\
\text { Estimation Method }\end{array}$} & \multicolumn{2}{|c|}{ Departures Scheduled } & \multicolumn{2}{|c|}{ Seats per Departure } \\
\hline & OLS & 2SLS & OLS & $2 \mathrm{SLS}$ \\
\hline & (a) & (b) & (c) & (d) \\
\hline Intercept & $\begin{array}{c}-164.66^{*} \\
(8.544)\end{array}$ & $\begin{array}{c}-128.48^{*} \\
(19.316)\end{array}$ & $\begin{array}{c}113.19^{*} \\
(4.256)\end{array}$ & $\begin{array}{c}112.44^{*} \\
(9.350)\end{array}$ \\
\hline \multicolumn{5}{|l|}{$\underline{\text { Time Control Variables }}$} \\
\hline 1st Quarter & $\begin{array}{l}-0.620 \\
(0.996)\end{array}$ & $\begin{array}{c}-21.118^{*} \\
(2.640)\end{array}$ & $\begin{array}{l}2.610^{*} \\
(0.506)\end{array}$ & $\begin{array}{c}-6.245^{*} \\
(0.797)\end{array}$ \\
\hline 2nd Quarter & $\begin{array}{l}6.618^{*} \\
(0.985)\end{array}$ & $\begin{array}{c}13.214^{*} \\
(2.292)\end{array}$ & $\begin{array}{l}2.897^{*} \\
(0.500)\end{array}$ & $\begin{array}{l}6.601^{*} \\
(1.109)\end{array}$ \\
\hline 3rd Quarter & $\begin{array}{l}3.115^{*} \\
(0.982)\end{array}$ & $\begin{array}{c}22.394^{*} \\
(2.806)\end{array}$ & $\begin{array}{l}0.690 \\
(0.499)\end{array}$ & $\begin{array}{c}-11.206^{*} \\
(1.358)\end{array}$ \\
\hline \multicolumn{5}{|l|}{ Population Characteristics } \\
\hline Origin Population & $\begin{array}{l}0.688^{*} \\
(0.015)\end{array}$ & $\begin{array}{l}0.239^{*} \\
(0.045)\end{array}$ & $\begin{array}{l}0.080^{*} \\
(0.008)\end{array}$ & $\begin{array}{l}0.010 \\
(0.022)\end{array}$ \\
\hline Destination Population & $\begin{array}{l}0.719^{*} \\
(0.016)\end{array}$ & $\begin{array}{l}0.270^{*} \\
(0.045)\end{array}$ & $\begin{array}{l}0.058^{*} \\
(0.008)\end{array}$ & $\begin{array}{l}-0.103 \\
(0.0223)\end{array}$ \\
\hline Origin Income above $\$ 75,000$ & $\begin{array}{l}2.672^{*} \\
(0.078)\end{array}$ & $\begin{array}{l}1.306^{*} \\
(0.195)\end{array}$ & $\begin{array}{l}1.015^{*} \\
(0.040)\end{array}$ & $\begin{array}{l}0.340^{*} \\
(0.094)\end{array}$ \\
\hline Destination Income above $\$ 75,000$ & $\begin{array}{l}2.640^{*} \\
(0.081)\end{array}$ & $\begin{array}{l}1.239^{*} \\
(0.201)\end{array}$ & $\begin{array}{l}0.767^{*} \\
(0.041)\end{array}$ & $\begin{array}{c}0.089 \\
(0.097)\end{array}$ \\
\hline Origin Percent Managers & $\begin{array}{c}19.457^{*} \\
(1.303)\end{array}$ & $\begin{array}{c}13.740^{*} \\
(2.844)\end{array}$ & $\begin{array}{c}-1.541^{*} \\
(0.661)\end{array}$ & $\begin{array}{c}-2.242^{* * *} \\
(1.370)\end{array}$ \\
\hline Destination Percent Managers & $\begin{array}{c}24.018^{*} \\
(1.463)\end{array}$ & $\begin{array}{c}18.308^{*} \\
(3.242)\end{array}$ & $\begin{array}{c}-1.671^{* *} \\
(0.742)\end{array}$ & $\begin{array}{c}-2.120 \\
(1.560)\end{array}$ \\
\hline Origin Percent Young & $\begin{array}{l}0.995^{*} \\
(0.148)\end{array}$ & $\begin{array}{l}2.705^{*} \\
(0.367)\end{array}$ & $\begin{array}{c}-1.860^{*} \\
(0.075)\end{array}$ & $\begin{array}{c}-0.883^{*} \\
(0.178)\end{array}$ \\
\hline Destination Percent Young & $\begin{array}{l}1.056^{*} \\
(0.151)\end{array}$ & $\begin{array}{l}2.982^{*} \\
(0.375)\end{array}$ & $\begin{array}{c}-1.686^{*} \\
(0.076)\end{array}$ & $\begin{array}{c}-0.655^{*} \\
(0.181)\end{array}$ \\
\hline \multicolumn{5}{|l|}{ Airport Characteristics } \\
\hline Origin Maximum Runway Length & $\begin{array}{l}0.862^{*} \\
(0.200)\end{array}$ & $\begin{array}{l}1.008^{*} \\
(0.463)\end{array}$ & $\begin{array}{l}1.520^{*} \\
(0.102)\end{array}$ & $\begin{array}{l}0.945^{*} \\
(0.224)\end{array}$ \\
\hline Destination Maximum Runway Length & $\begin{array}{l}1.147^{*} \\
(0.197)\end{array}$ & $\begin{array}{l}0.126 \\
(0.454)\end{array}$ & $\begin{array}{l}1.367^{*} \\
(0.100)\end{array}$ & $\begin{array}{l}0.974^{*} \\
(0.220)\end{array}$ \\
\hline Vicinity Airports near Origin & $\begin{array}{c}-9.237^{*} \\
(0.314)\end{array}$ & $\begin{array}{c}-3.026^{*} \\
(0.832)\end{array}$ & $\begin{array}{c}-2.047^{*} \\
(0.159)\end{array}$ & $\begin{array}{l}-0.314 \\
(0.403)\end{array}$ \\
\hline Vicinity Airports near Destination & $\begin{array}{c}-8.415^{*} \\
(0.308)\end{array}$ & $\begin{array}{c}-2.607^{*} \\
(0.797)\end{array}$ & $\begin{array}{c}-2.876^{*} \\
(0.156)\end{array}$ & $\begin{array}{c}-1.130^{*} \\
(0.386)\end{array}$ \\
\hline Cancellations at Origin & $\begin{array}{l}0.057^{*} \\
(0.002)\end{array}$ & $\begin{array}{l}0.552^{*} \\
(0.056)\end{array}$ & $\begin{array}{l}0.009^{*} \\
(0.001)\end{array}$ & $\begin{array}{l}0.286^{*} \\
(0.027)\end{array}$ \\
\hline Cancellations at Destination & $\begin{array}{l}0.056^{*} \\
(0.002)\end{array}$ & $\begin{array}{l}0.541^{*} \\
(0.045)\end{array}$ & $\begin{array}{l}0.009^{*} \\
(0.001)\end{array}$ & $\begin{array}{l}0.197^{*} \\
(0.022)\end{array}$ \\
\hline \multicolumn{5}{|l|}{ Airline Characteristics } \\
\hline Number of Destinations from Origin & $\begin{array}{l}0.476^{*} \\
(0.020)\end{array}$ & $\begin{array}{c}-1.355^{*} \\
(0.144)\end{array}$ & $\begin{array}{l}0.155^{*} \\
(0.010)\end{array}$ & $\begin{array}{c}-0.548^{*} \\
(0.070)\end{array}$ \\
\hline Number of Destinations from Destination & $\begin{array}{l}0.432^{*} \\
(0.020)\end{array}$ & $\begin{array}{c}-1.277^{*} \\
(0.151)\end{array}$ & $\begin{array}{l}0.173^{*} \\
(0.010)\end{array}$ & $\begin{array}{c}-0.654^{*} \\
(0.073)\end{array}$ \\
\hline Share of Connecting Passengers at Origin & $\begin{array}{c}29.952^{*} \\
(4.524)\end{array}$ & $\begin{array}{l}69.431^{*} \\
(10.535)\end{array}$ & $\begin{array}{l}7.854^{*} \\
(2.296)\end{array}$ & $\begin{array}{c}23.285^{*} \\
(5.102)\end{array}$ \\
\hline Share of Connecting Passengers at Destination & $\begin{array}{c}17.513^{*} \\
(4.478)\end{array}$ & $\begin{array}{l}42.518^{*} \\
(10.190)\end{array}$ & $\begin{array}{l}7.183^{*} \\
(2.273)\end{array}$ & $\begin{array}{c}12.686^{*} \\
(4.934)\end{array}$ \\
\hline Low Cost Carrier & $\begin{array}{l}42.209^{*} \\
(1.099)\end{array}$ & $\begin{array}{l}7.663^{*} \\
(3.159)\end{array}$ & $\begin{array}{c}40.050^{*} \\
(0.558)\end{array}$ & $\begin{array}{c}25.307^{*} \\
(1.530)\end{array}$ \\
\hline \multicolumn{5}{|l|}{$\underline{\text { Route Characteristics }}$} \\
\hline Distance & $\begin{array}{c}-58.360^{*} \\
(0.663)\end{array}$ & $-\underset{(2.567)}{26.246^{*}}$ & $\begin{array}{c}30.675^{*} \\
(0.336)\end{array}$ & $\begin{array}{c}46.080^{*} \\
(1.243)\end{array}$ \\
\hline Leisure Route & $\begin{array}{c}31.686^{*} \\
(1.460)\end{array}$ & $\begin{array}{c}31.724^{*} \\
(3.209)\end{array}$ & $\begin{array}{c}15.369^{*} \\
(0.741)\end{array}$ & $\underset{(1.554)}{13.374^{*}}$ \\
\hline Observations & 41,353 & & 41,353 & \\
\hline$R^{2}$ & 0.348 & .319 & 0.346 & 0.143 \\
\hline $\operatorname{Adj} R^{2}$ & 0.347 & .318 & 0.346 & 0.142 \\
\hline
\end{tabular}




\section{References}

[1] Babikian, R., Lukacho, S.P., Waitz, I.A. (2002) The historical fuel efficiency characteristics of regional aircraft from technological, operational, and cost perspectives. Journal of Air Transport Management 8, 389-400.

[2] Bhadra, D. (2005), Choice of Aircraft Fleets in the U.S. Domestic Scheduled Air Transportation System: Findings from a Multinomial Logit Analysis, Journal of the Transportation Research Forum, Fall 2005

[3] Brueckner, J.K (2004). Network structure and airline scheduling. Journal of Industrial Economics 52, 291-311.

[4] Brueckner, J.K, and Flores-Fillol, R (2007). Airline Schedule Competition. Review of Industrial Organization, 30, 161-177

[5] Brueckner, J.K, and Pai, V (2007). Technological Innovation in the Airline Industry: The Impact of Regional Jets. Department of Economics Working Paper, University of California, Irvine.

[6] Dresner, M., Windle, R., Zhou, M. (2002a). Regional jet services: supply and demand. Journal of Air Transport Management 8, 267-273

[7] Dresner M., Windle, R., Zhou, M. (2002b). Airport barriers to entry in the US. Journal of Transport Economics and Policy, 36, 389-405.

[8] Forbes, S.J., Lederman, M. (2005). Control rights, network structure and vertical integration: Evidence from regional airlines. Unpublished paper, University of California, San Diego.

[9] Rupp, N.G. (2005). Flight Delays and Cancellations. Department of Economics Working Paper, East Carolina University

[10] Rupp, N., Holmes, G.M., (2007). An Investigation Into the Determinants of Flight Cancellations. Forthcomming, Economica

[11] Wei W. and Hansen M. (2003) Cost economics of aircraft size. Journal of Transport Economics and Policy, 37, 279-296. 


\section{Appendix}

\subsection{Census}

Demographic data for this analysis comes from the 2000 Census data gathered from the 2007 State and Metropolitan databook. Airports were assigned to a metropolitan statistical area (MSA) based on the name of the airport. Most airports identify themselves as serving a specific city, and therefore a matching MSA, making the assignment of census data unambiguous. However, ambiguity arises in two special cases: (i) where one airport serves multiple MSAs, and (ii) where multiple airports serve a given MSA.

In case (i), the population-weighted average of the demographic data for the relevant MSAs was computed. Affected airports were CAK, where the Akron, $\mathrm{OH}$ and Canton-Massillon, $\mathrm{OH}$ MSAs were combined; ELM, where the Corning, NY and Elmira, NY MSAs were combined; MAF, where the Midland, TX and Odessa, TX MSAs were combined; RDU, where the Raleigh and Durham, NC MSAs were combined. For the Hartford-Springfield International Airport, BDL, the airport was assigned to the Hartford, CT, MSA due to the longer distance to Springfield, MA.

In case (ii), the same MSA was assigned to each airport in the area, unless it was possible to assign a Metropolitan Division to the airport. For the Los Angeles MSA, Los Angeles International (LAX) was assigned to the Los Angeles Metropolitan Division and Orange County John Wayne (SNA) to the Santa Ana-Anaheim-Irvine Division. For the San Francisco Bay Area, San Francisco International (SFO) was assigned to the San Francisco-San Mateo-Redwood City Division, and Oakland International (OAK) to the Oakland-Fremont-Hayward Division. San Jose Mineta International (SJC) was assigned to the San Jose-Sunnyvale-Santa Clara, CA MSA. In the Chicago area, O'Hare (ORD) and Midway (MDW) were assigned to the Chicago MSA. For the New York City area, LaGuardia (LGA), John F. Kennedy (JFK), and Newark (EWR) were assigned to the New York-North New Jersey-Long Island MSA. Islip (ISP) and White Plains (HPN) were assigned to the Nassau-Suffolk and New York-White Plains Metropolitan Divisions respectively.

Several airports do not fall into a MSA or could not be easily assigned to a Metropolitan Division in a large MSA, and for these cases, census data were gathered for the city in which airport is located. These airports are Traverse City, MI, Pasco, WA, Montrose, CO, Missoula, MT, Melbourne, FL, Jackson, WY, Helena, MT, Gunnison, CO, Bozeman, MT, Vail, CO, Kailspell, MT, Meridian, MS, Butte, MT, Hanover, NH Minot, ND, Harlingen, TX, Temple, TX, Cody, WY, Burbank, CA, Long Beach, CA, Palm Springs, CA, Aspen, CO, Durango, CO, Hayden, CO, KeyWest, FL,Marathon, FL, Brunswick, GA, Burlington, IA, Presque Isle, ME, Nantucket, MA. Due to the lack of available data, Martha's Vineyard and Hyannis, MA were assigned to their respective counties of Barnstable and Dukes. 


\subsection{Hub Cities via Number of Destinations and Connecting Share}

Table 8: Hub Cities for Network Carriers

\begin{tabular}{rlcc}
\hline \hline Major & Airport & Number of Destinations & Share of Connecting Passengers \\
\hline American & Dallas-Ft. Worth (DFW) & 126 & 0.47684 \\
& Chicago O'Hare (ORD) & 99 & 0.33761 \\
& St. Louis (STL) & 66 & 0.23641 \\
Miami (MIA) & 38 & 0.12158 \\
Los Angeles Int'l (LAX) & 24 & 0.14046 \\
New York LaGuardia (LGA) & 24 & 0.03106 \\
Boston (BOS) & 21 & 0.02420 \\
Raleigh-Durham (RDU) & 14 & 0.02580 \\
New York JFK (JFK) & 11 & 0.04009 \\
Washington National (DCA) & 9 & 0.03656 \\
Memphis (BNA) & 9 & 0.02662 \\
Seattle (SEA) & 44 & 0.20299 \\
Plaskatland (PDX) & 28 & 0.15554 \\
Denver (DEN) & 16 & 0.27356 \\
Los Angeles Int'l (LAX) & 11 & 0.09976 \\
Boise (BOI) & 10 & 0.12585 \\
Spokane (GEG) & 5 & 0.02234 \\
San Francisco (SFO) & 4 & 0.11657 \\
Sacramento (SMF) & 4 & 0.04206 \\
San Jose (SJC) & 4 & 0.03367 \\
Palm Springs (PSP) & 4 & 0.00719 \\
\hline
\end{tabular}




\begin{tabular}{|c|c|c|c|}
\hline Major & Airport & Number of Destinations & Share of Connecting Passengers \\
\hline \multirow[t]{16}{*}{ Continental } & Houston Bush Intercontinental (IAH) & 119 & 0.40066 \\
\hline & Newark (EWR) & 76 & 0.08643 \\
\hline & Cleveland Hopkins (CLE) & 74 & 0.23353 \\
\hline & Boston (BOS) & 13 & 0.02228 \\
\hline & Albany (ALB) & 10 & 0.03869 \\
\hline & Tampa (TPA) & 6 & 0.05831 \\
\hline & Westchester Co, NY(HPN) & 5 & 0.03186 \\
\hline & Ft Myers, FL (RSW) & 5 & 0.01299 \\
\hline & Rochester (ROC) & 4 & 0.06341 \\
\hline & Syracuse (SYR) & 4 & 0.04728 \\
\hline & Ft Lauderdale (FLL) & 4 & 0.03522 \\
\hline & Miami (MIA) & 4 & 0.03451 \\
\hline & Burlington (BTV) & 4 & 0.03013 \\
\hline & Baltimore (BWI) & 4 & 0.02837 \\
\hline & Sarasota (SRQ) & 4 & 0.01653 \\
\hline & Portland, ME (PWM) & 4 & 0.01316 \\
\hline \multirow[t]{10}{*}{ Delta } & Atlanta (ATL) & 155 & 0.5202 \\
\hline & Cincinnati (CVG) & 124 & 0.61452 \\
\hline & Salt Lake City (SLC) & 78 & 0.36503 \\
\hline & Orlando (MCO) & 48 & 0.05063 \\
\hline & Dallas-Ft. Worth (DFW) & 38 & 0.05964 \\
\hline & New York JFK (JFK) & 36 & 0.04308 \\
\hline & Ft Lauderdale (FLL) & 25 & 0.01997 \\
\hline & Tampa (TPA) & 24 & 0.03057 \\
\hline & Boston (BOS) & 23 & 0.02281 \\
\hline & New York LaGuardia (LGA) & 23 & 0.01859 \\
\hline \multirow[t]{18}{*}{ Northwest } & Minneapolis-St Paul (MSP) & 137 & 0.45065 \\
\hline & Detroit (DTW) & 125 & 0.44509 \\
\hline & Memphis (MEM) & 86 & 0.66343 \\
\hline & Indianapolis (IND) & 20 & 0.06498 \\
\hline & Milwaukee (MKE) & 15 & 0.05019 \\
\hline & Washington Reagan (DCA) & 7 & 0.02163 \\
\hline & Las Angeles (LAX) & 6 & 0.06247 \\
\hline & Las Vegas (LAS) & 6 & 0.02272 \\
\hline & Orlando (MCO) & 6 & 0.01729 \\
\hline & St Louis (STL) & 5 & 0.03032 \\
\hline & Denver (DEN) & 5 & 0.02807 \\
\hline & Tampa (TPA) & 5 & 0.02695 \\
\hline & New York LaGaurdia (LGA) & 5 & 0.02213 \\
\hline & Kansas City, MO (MCI) & 5 & 0.02161 \\
\hline & Flint (FNT) & 5 & 0.02037 \\
\hline & Ft Lauderdale (FLL) & 5 & 0.01745 \\
\hline & Ft Myers, FL (RSW) & 5 & 0.00769 \\
\hline & Boston (BOS) & 5 & 0.00757 \\
\hline
\end{tabular}




\begin{tabular}{|c|c|c|c|}
\hline Major & Airport & Number of Destinations & Share of Connecting Passengers \\
\hline \multirow{22}{*}{ US Airways } & Chicago O'Hare (ORD) & 110 & 0.35742 \\
\hline & Denver (DEN) & 88 & 0.40310 \\
\hline & Washington Dullas (IAD) & 64 & 0.19418 \\
\hline & San Francisco (SFO) & 44 & 0.20823 \\
\hline & Los Angeles Int'l (LAX) & 40 & 0.21023 \\
\hline & Salt Lake City (SLC) & 14 & 0.67047 \\
\hline & Portland, OR (PDX) & 10 & 0.07273 \\
\hline & Seattle (SEA) & 8 & 0.05637 \\
\hline & Las Vegas (LAS) & 7 & 0.10675 \\
\hline & Phoenix (PHX) & 6 & 0.17216 \\
\hline & San Diego (SAN) & 6 & 0.04188 \\
\hline & Sacramento (SMF) & 6 & 0.03936 \\
\hline & Charlotte (CLT) & 93 & 0.62698 \\
\hline & Philadelphia (PHL) & 81 & 0.27806 \\
\hline & Phoenix (PHX) & 75 & 0.39992 \\
\hline & Pittsburgh (PIT) & 62 & 0.22192 \\
\hline & Las Vegas (LAS) & 57 & 0.18202 \\
\hline & Washington National (DCA) & 47 & 0.18788 \\
\hline & New York LaGuardia (LGA) & 36 & 0.09671 \\
\hline & Boston (BOS) & 27 & 0.02319 \\
\hline & Hartford (BDL) & 25 & 0.01202 \\
\hline & Syracuse (SYR) & 24 & 0.01702 \\
\hline Major & Airport & Number of Destinations & Share of Connecting Passengers \\
\hline \multirow[t]{25}{*}{ Jetblue } & New York JFK (JFK) & 24 & 0.06719 \\
\hline & Boston (BOS) & 12 & 0.00060 \\
\hline & Long Beach (LGB) & 7 & 0.01338 \\
\hline & Ft Lauderdale (FLL) & 6 & 0.00086 \\
\hline & Washington Dulles (IAD) & 5 & 0.00610 \\
\hline & Oakland (OAK) & 4 & 0.00280 \\
\hline & West Palm Beach (PBI) & 4 & 0.00019 \\
\hline & Las Vegas (LAS) & 3 & 0.00683 \\
\hline & Orlando (MCO) & 3 & 0.00014 \\
\hline & Tampa (TPA) & 3 & 0.00008 \\
\hline & Ft Myers (RSW) & 3 & 0 \\
\hline & Atlanta (ATL) & 46 & 0.39972 \\
\hline & Orlando (MCO) & 17 & 0.00083 \\
\hline & Baltimore (BWI) & 11 & 0.06214 \\
\hline & Tampa (TPA) & 11 & 0.00068 \\
\hline & Philadelphia (PHL) & 8 & 0.01565 \\
\hline & Ft Lauderdale (FLL) & 7 & 0.00035 \\
\hline & Dallas-Ft Worth (DFW) & 6 & 0.01531 \\
\hline & Boston (BOS) & 6 & 0.00100 \\
\hline & Ft Myers (RSW) & 6 & 0.00063 \\
\hline & Akron/Canton (CAK) & 5 & 0.00956 \\
\hline & Hampton, VA (PHF) & 5 & 0.00718 \\
\hline & Chicago Midway (MDW) & 5 & 0.00634 \\
\hline & Rochester (ROC) & 5 & 0.00036 \\
\hline & Sarasota, FL (SRQ) & 5 & 0.00035 \\
\hline
\end{tabular}




\begin{tabular}{rlcc}
\hline \hline Major & Airport & Number of Destinations & Share of Connecting Passengers \\
\hline ATA & Chicago Midway (MDW) & 26 & 0.25645 \\
& Indianapolis (IND) & 16 & 0.00700 \\
& Phoenix (PHX) & 3 & 0.23817 \\
& Las Vegas (LAS) & 2 & 0.09120 \\
Denver (DEN) & 2 & 0.05906 \\
Orlando (MCO) & 2 & 0.04029 \\
& Dallas-Ft Forth (DFW) & 2 & 0.02928 \\
Las Angeles (LAX) & 2 & 0.01896 \\
New York LaGaurdia (LGA) & 2 & 0.01379 \\
Ft Myers, FL (RSW) & 2 & 0.00161 \\
Lauthwest Vegas (LAS) & 49 & 0.26799 \\
Chicago Midway (MDW) & 42 & 0.27708 \\
Phoenix (PHX) & 39 & 0.26699 \\
Baltimore (BWI) & 34 & 0.24998 \\
Nashville (BNA) & 27 & 0.25068 \\
Orlando (MCO) & 27 & 0.12897 \\
Houston (HOU) & 26 & 0.29152 \\
Tampa (TPA) & 25 & 0.13348 \\
St Louis (STL) & 21 & 0.20217 \\
Albuquerque (ABQ) & 21 & 0.16704 \\
Los Angeles Intl (LAX) & 21 & 0.11423 \\
Oakland (OAK) & 20 & 0.06930 \\
Kansas City, MO (MCI) & 19 & 0.16761 \\
\hline
\end{tabular}

